\title{
Contextualizando as imagens na sala de aula
}

\author{
Clarinda Conceição Rocha de Sousa ${ }^{1}$ \\ Glaucia Muñoz dos Reis ${ }^{2}$ \\ Márcia Tostes Costa da Silva ${ }^{3}$
}

\begin{abstract}
RESUMO
Este artigo propõe uma breve reflexão acerca das imagens presentes no cotidiano escolar, contidas especialmente nos livros didáticos; as quais, quando não contextualizadas adequadamente pelo professor, podem conduzir o aluno a compreensões limitadas, muitas vezes distorcidas, direcionando suas leituras de mundo. Tomando como aporte teórico, Saliba (2011), e contribuições de outros autores, como Barbosa (2012), Franca (2006), Coli (1995), Mosaner Jr e Stori (2007), Benjamin (1955), Morin (2003) e Lenoir (1998), buscamos abordar alguns aspectos sobre o "olhar" nessas imagens, ditas por Saliba como imagens canônicas, bem como o excesso das imagens apresentadas em sala de aula. Procuramos propor um estudo de conteúdo interdisciplinar que faça do ensino de Arte algo integrado em um contexto escolar, que redireciona o olhar das imagens estudadas para um processo de criação e possibilitando ao aluno se colocar como autor da história.
\end{abstract}

Palavras-chave: Arte; educação; contextualização; imagens canônicas; interdisciplinaridade.

\section{ABSTRACT}

This article offers a brief reflection about the images in everyday school life, especially contained in textbooks; which, when not properly contextualized by the teacher, the student can lead to limited understanding, often distorted, directing their perceptions of the world. Having Saliba's (2011) as a theoretical support and other authors' contributions, such as Barbosa (2012), Franca (2006), Coli (1995), Mosaner Jr and Stori (2007), Benjamin (1955), Morin (2003) and Lenoir (1998), our approach relies on some aspects about the "look" of the images named as canonical by Saliba as well as the excess of images shown in the classroom. We seek to propose a study of interdisciplinary content way allowing to include the Art teaching in a school context was launched, which redirects the look of the studied images to a creating process and placing the student as the author of the story.

Keywords: Art; education; contextualization; canonical images; interdisciplinarity.

\footnotetext{
1 Arte educadora, integrante do Projeto Teatro de Bonecos "Mamulengo" da Secretaria Municipal de Educação (SME). Mestranda em Educação Arte e História da Cultura na Universidade Presbiteriana Mackenzie. Email: clarinda.arte@gmail.com

2 Pedagoga pela Universidade Presbiteriana Mackenzie. Mestranda em Educação Arte e História da Cultura na Universidade Presbiteriana Mackenzie. E-mail: glaumreis@hotmail.com

3 Pedagoga pela Universidade Presbiteriana Mackenzie. Mestranda em Educação Arte e História da Cultura na Universidade Presbiteriana Mackenzie. Email: tostes.silva66@gmail.com
} 


\section{Introdução}

As imagens apresentadas no ambiente escolar, em forma de pinturas, gravuras, ilustrações, charges, ou contidas nos filmes publicitários e nos longas-metragens, exercem grande influência sobre os alunos, direcionando interpretações e compreensões muitas vezes equivocadas, quando não contextualizadas aos conteúdos abordados em sala de aula. A linguagem visual tem a capacidade de comunicar ideias e pensamentos de modo atraente e imediato, conduzindo mais facilmente à compreensão dos conteúdos, com os quais está relacionada. Mas, ao mesmo tempo em que facilita a compreensão, igualmente pode limitar o imaginário do aluno, fixando sua visão sobre o assunto abordado pelo professor à imagem apresentada.

Geralmente os livros didáticos e as apostilas que utilizamos na escola, principalmente os da disciplina de História, estão repletos de imagens que ilustram os fatos e os conceitos apresentados. Normalmente a escolha dessas imagens está atrelada a certos objetivos e ideologias que o autor quer disseminar, que na maioria das vezes não estão explícitos no material que contém a obra. Em certos casos, o uso das imagens pode estar associado a simples fatores como: dar visibilidade ao texto, para melhor explicá-lo, deixar os livros coloridos e mais apreciáveis, ou até mesmo para tornar o ato da leitura mais ameno e possibilitar maior interesse dos alunos pela aprendizagem de história.

Deseja-se chamar atenção aqui para o fato de professores e alunos passarem por imagens sem ao menos deterem-se em apreciá-las, pois "precisam" terminar de estudar os conteúdos que foram determinados, em um tempo pré-fixado. Essa pressa os impede de compreender a contextualidade, a representatividade e o simbolismo da obra.

\section{Analisando as imagens canônicas}

Após a década de 1970, houve uma tentativa de modernização dos livros didáticos, incluindo mapas, caricaturas, fotografias. Porém, algumas imagens de pinturas do final do século XIX e início do século XX permaneceram nos livros didáticos.

Muitas dessas imagens são denominadas por Saliba (2011) como imagens canônicas que acabam por agir de modo subliminar. Elas são incorporadas ao imaginário coletivo e logo identificadas. $\mathrm{O}$ autor menciona várias imagens que pertencem a esse grupo, tido por ele como imagens canônicas e identificadas como ligadas ao acontecimento, sem serem apreciadas e criticadas. Tais imagens são verdadeiras obras de arte que são esquecidas em livros e não fazem parte de um estudo crítico por parte dos educadores e educandos. Como exemplo, podemos citar a obra que retrata Tiradentes com barba, que ficou vinculado ao imaginário. Essa imagem retrata o mártir brasileiro, comparada à imagem também canônica conhecida de Jesus Cristo. Alguns quadros de Tiradentes sem barba, segundo Saliba (2011, p. 88) tentam desmitificar a outra, que, segundo ele, é fruto de uma ideologia republicana:

A imagem de Tiradentes sem barba, vinculada em alguns raros quadros que tentam quebrar um pouco a imagem de mártir - ou em filmes como Os inconfidentes, de Joaquim Pedro de Andrade, de 1972, já é desmistificadora, pois sabemos que a barba de Tiradentes foi uma criação bem mais tardia, da república brasileira, na época de sua fundação. 


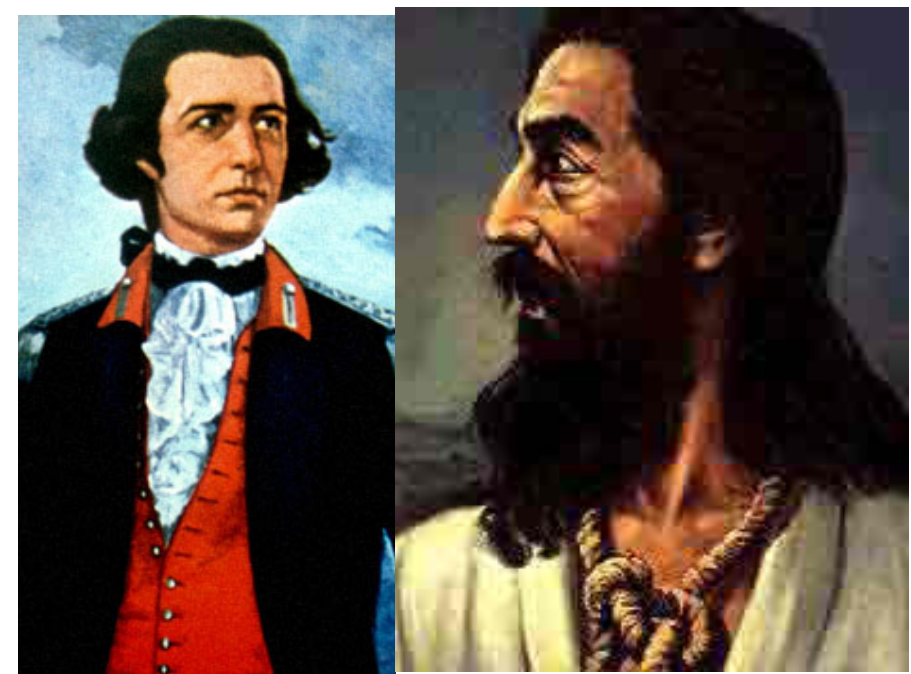

José Wasth Rodrigues (1891-1957).

Alberto André Feijó Delpino (1864 - 1942).

"Alferes Joaquim José da Silva Xavier, o Tiradentes" (detalhe),1940. Óleo sobre tela, $156,5 \mathrm{~cm}$ X98 cm. Museu Histórico Nacional, RJ.

"Tradentes enforcado". Tornou-se o retrato oficial de Tiradentes.

Disponível em: http://pt.wikipedia.org/wiki/Alberto_Delpino

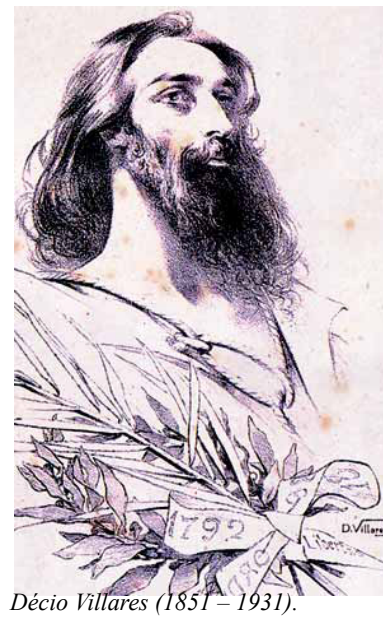

'Tiradentes". Litogravura, 1890.

Museu Histórico Nacional, RJ.

Semelhança com a imagem de Jesus.

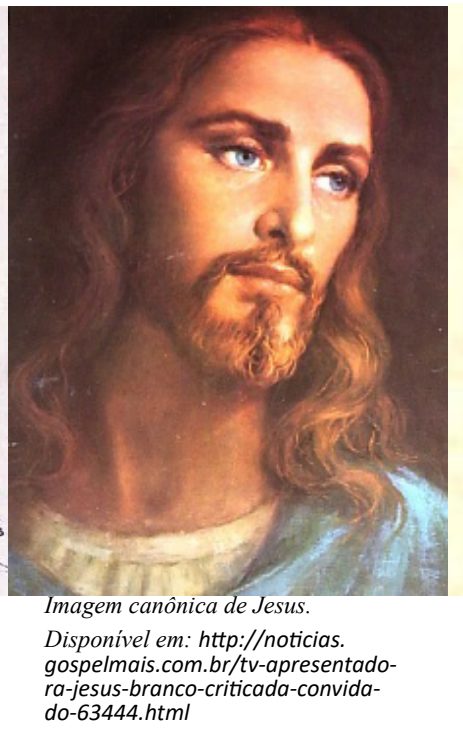
ra-jesus-branco-criticada-convida-
do-63444.html

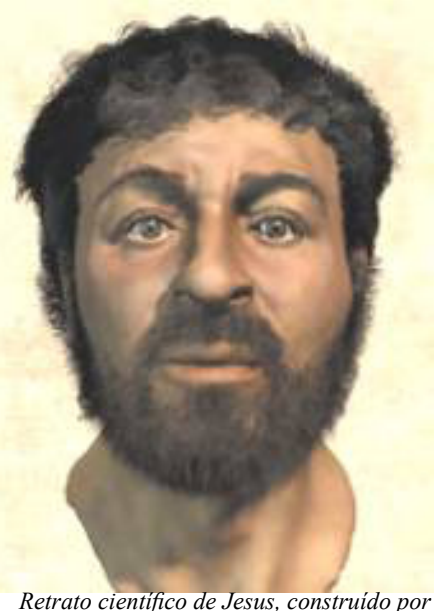

Retrato cientifico de Jesus, construido por cientistas com auxilio da antropologia e recursos tecnológicos.

Disponivel em: http://www.espirito.org.br/ portal/artigos/correio-fraterno/retrato-dejesus.html

Outra imagem recorrente nos livros de História da época da ditadura é o quadro "Independência ou Morte", conhecido como "Grito do Ipiranga", de Pedro Américo, pintado em 1888, 66 anos após a Proclamação da Independência. Ele recebeu ao longo do tempo muitas críticas, como acusação de plágio do quadro que retrata a vitória de Napoleão Bonaparte, em 1807, em Friendland, pintado por Ernest Meissonier, em 1875, e outras que desmitificam o momento, como o tipo de roupas e montaria, o relevo, a posição geográfica do riacho do Ipiranga e a casa que foi construída anos após o ocorrido. 


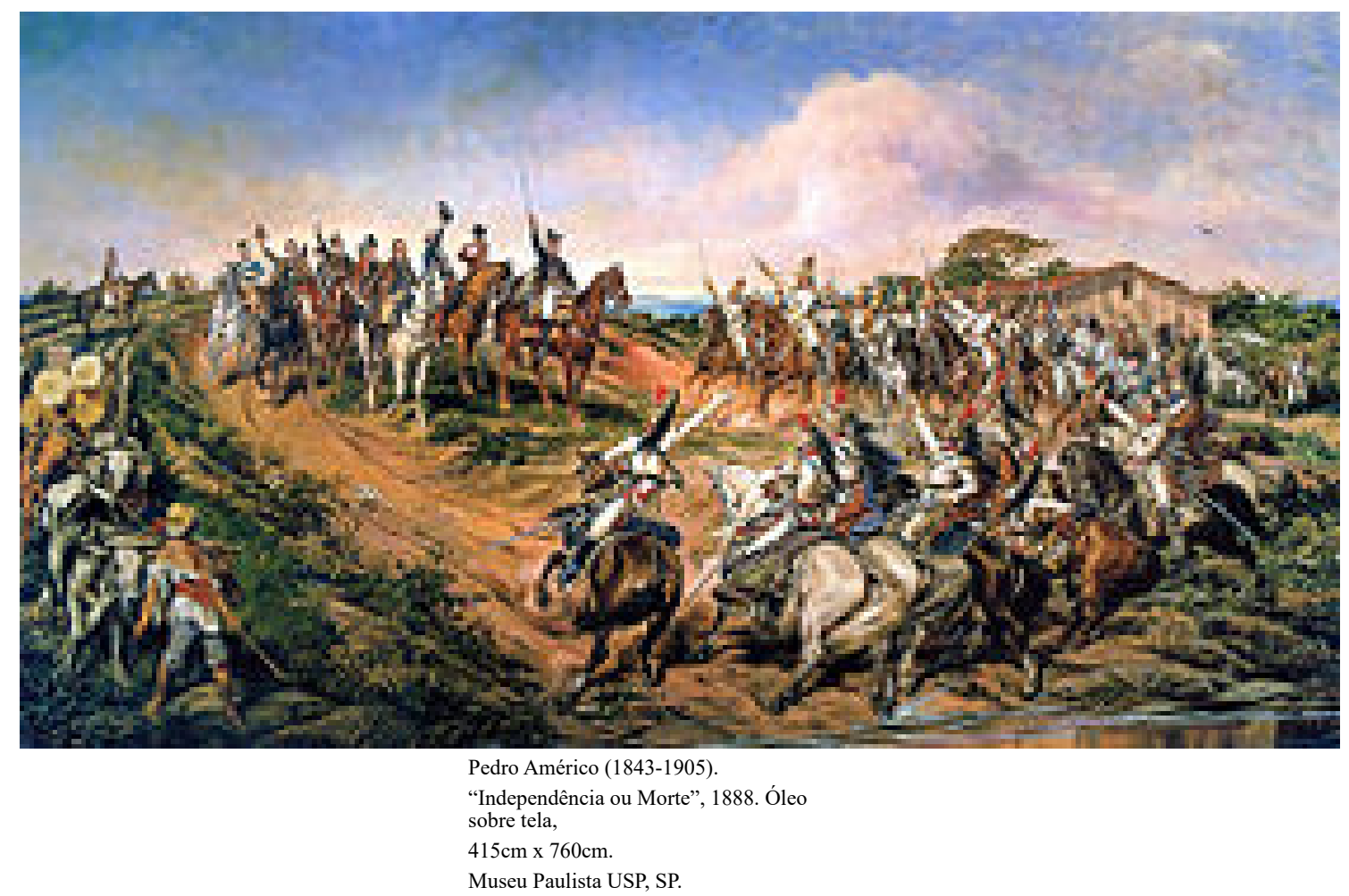

Além de algumas dessas imagens não retratarem o que realmente aconteceu, existe outra questão importante que deve ser levada em consideração em relação à imagem, que é a sua reprodução, pois ao serem produzidas em série, essas imagens vão perdendo a sua autenticidade e, como aponta Benjamin (1955), "Na medida em que se ela multiplica a reprodução, substitui a existência única dá obra por uma existência serial". Sendo assim, mesmo que ocorra uma reprodução perfeita, segundo o autor, a obra perderá um elemento essencial que é o 'aqui e agora da obra de arte', a existência única e a sua reconstituição e a compreensão somente ocorrerá se tomar como ponto de partida o lugar onde se encontrava no original".

Neste sentido, Saliba corrobora com esse pensamento quando atribui à imagem canônica o conceito de imagem coerciva:

(...) a imagem canônica - é coercitiva. Coercitiva porque nos impunha uma figura reproduzida infinitamente em série, tão infinitamente repetitiva que não mais nos provocava nenhuma estranheza, bloqueava nossa possibilidade de uma representação alternativa, ou seja, não nos levava mais a distinguir e comparar, em suma não nos levava mais a pensar. (SALIBA, 2011, p. 88).

Retomando as análises das imagens de Tiradentes, Saliba (2011) argumenta que tais imagens são retratadas de modo recorrente nos livros da década de 1970, em plena ditadura militar, esquartejado e com as partes de seu corpo expostas; ideia, esta, que permaneceu em nossa memória como uma imagem canônica. 


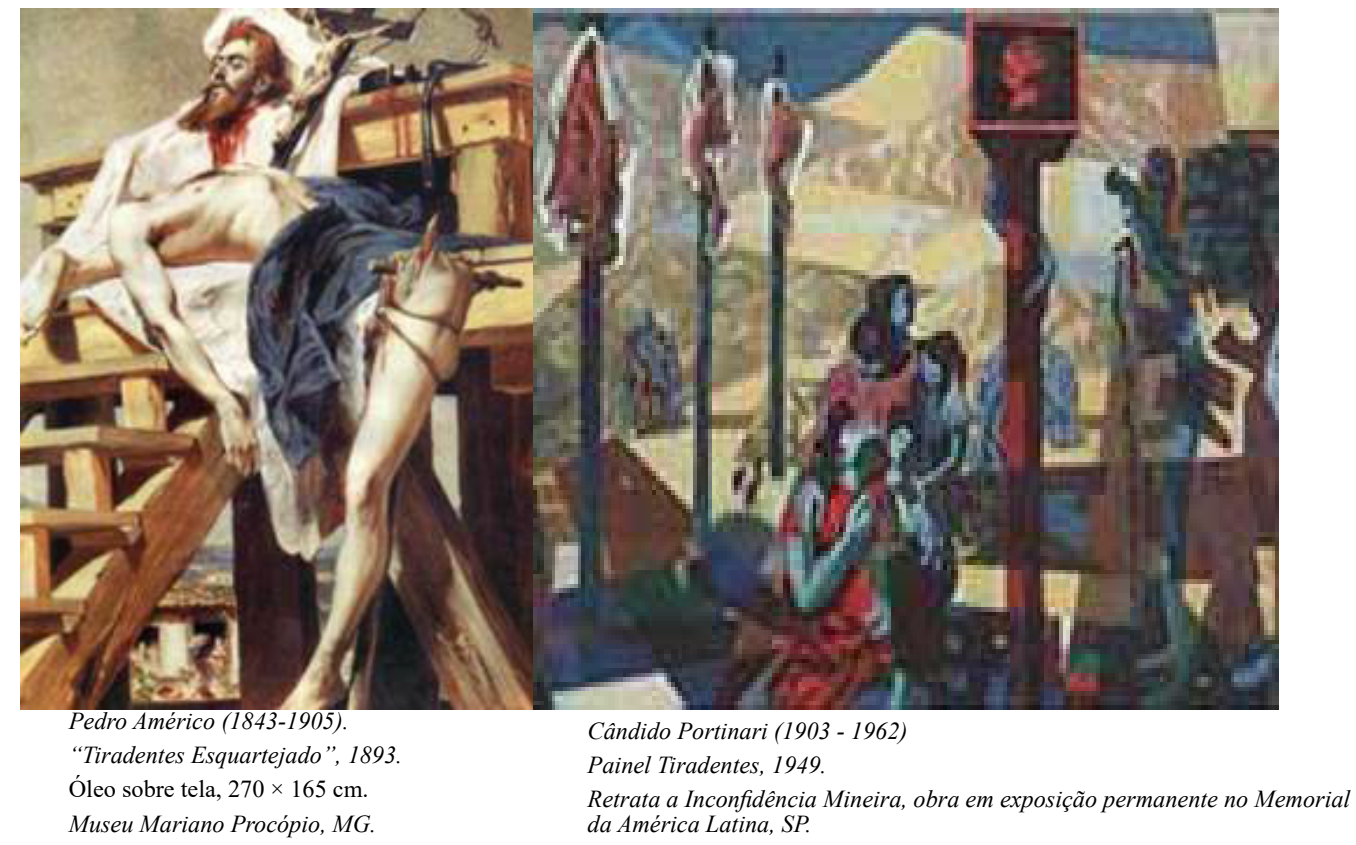

A crítica não está no fato de essas imagens fazerem parte dos livros didáticos e sim no desprezo ao contexto em que essas obras foram produzidas; deixando de considerar os acontecimentos a que estão relacionadas, o motivo pelo qual o autor as produziu, o que o inspirou e se realmente a obra está se referindo ao fato narrado no texto que a acompanha.

Sendo assim, a retratação do fato histórico pode não ser a expressão da realidade, mas a obra e seus objetivos o são e não devem ser desconsiderados, mas apresentados ao estudante para discussão e apreciação, mesmo quando se tem conhecimento de que essas obras de arte foram encomendadas anos após o ocorrido, visando a atender objetivos específicos que envolviam os fatores políticos, econômicos e sociais. Contudo, a beleza e a "veracidade" da obra são legítimas, se analisadas e apreciadas a partir do contexto em que foram produzidas.

No entanto, seguindo naanálise das imagens dos livros didáticos atuais, percebemosuma mudança gradativa na apresentação das suas imagens. Isso se evidencia quando um desses livros utiliza ao mesmo tempo as antigas imagens canônicas de Tiradentes (com barba e sem barba) e de seu esquartejamento (Tiradentes esquartejado, de Pedro Américo, 1893), com a devida explicação do contexto (o fato histórico narrado e a real apresentação dos fatos), esclarecendo que as partes do corpo não foram expostas juntas como mostra a pintura de Pedro Américo. O detalhe do Painel de Cândido Portinari (Despojos de Tiradentes, de 1947) apresenta outra visão sobre o ocorrido com Tiradentes.

As duas obras são apresentadas ao aluno, dando oportunidade de apreciação e compreensão sobre o contexto em que elas foram produzidas, sem a emissão de opinião de valor ou preferência sobre as obras.

Coli (1995) salienta que é necessário vincular a apreciação à obra com a história que ela contempla, e afirma a importância de estarmos perto da obra:

(...) é necessário algum conhecimento da história do Brasil para penetrar no sentido da Primeira Missa ou do Tiradentes, temas tão caros à nossa pintura, de Vitor Meireles a Pedro Américo e 
Portinari. Podemos ainda comparar entre si quadros do mesmo autor; ou quadros do mesmo gênero; ou quadros de pintores que tenham afinidades com aquele que nos interessa. Podemos situar o pintor em sua cultura e seu tempo. Enfim: podemos enveredar por mil sendas diferentes: o essencial é nos mantermos, sempre, próximos à obra (COLI, 1995, p. 122).

Isso fica mais evidente quando se trata de imagens exibidas em sala de aula em um contexto específico de ensino de História.

Barbosa (2012) esclarece que contextualizar não é apenas explicar e falar sobre a vida do autor, a não ser que isso interfira na obra; para a autora, contextualizar é mais do que isso, ao se fazer arte é necessário ter a consciência do que foi feito e ao "ler" buscar a significação:

A contextualização sendo a condição epistemológica básica de nosso momento histórico, como a maioria dos teóricos contemporâneos da educação comprova, não poderia ser vista como um dos lados ou um dos vértices do processo de aprendizagem. O fazer arte exige contextualização, a qual é a conscientização do que foi feito, assim como qualquer leitura como processo de significação exige a contextualização para ultrapassar a mera apreensão do objeto (BARBOSA, 2012, p.33).

\section{Um olhar sobre as imagens}

Embora percebamos um avanço na apresentação da imagem nos livros, compreendemos que é de competência do professor propor ao aluno a observação da obra, contextualizando-a e refletindo sobre esta, questionando se ela realmente se refere ao fato descrito no livro, se é pertinente, se o que há na obra difere do fato. Quando e por que o artista pintou? Teria mesmo acontecido da forma como é apresentado no quadro?

A partir dessa postura do professor em relação ao tratamento dado a imagem, o aluno romperá com o pensamento que desune os conhecimentos, os descontextualiza, e desenvolverá aptidões para contextualizar e globalizar os saberes, como nos aponta Morin:

Como nosso modo de conhecimento desune os objetos entre si, precisamos conceber o que os une. Como ele isola os objetos de seu contexto natural e do conjunto do qual fazem parte, é uma necessidade cognitiva inserir um conhecimento particular em seu contexto e situá-lo em seu conjunto. De fato, a psicologia cognitiva demonstra que o conhecimento progride menos pela sofisticação, formalização e abstração dos conhecimentos particulares do que, sobretudo, pela aptidão a integrar esses conhecimentos em seu contexto global. A partir daí, o desenvolvimento da aptidão para contextualizar e globalizar os saberes torna-se um imperativo da educação. (MORIN, 2003, p. 24).

Levando em conta o que diz Morin (2003) a respeito de contextualizar e 
globalizar saberes, e partindo do pressuposto de que toda imagem é histórica e está inserida no tempo e no espaço, podemos nos referir à "marcha linear em escada da evolução da vida", citada por Saliba (2011, p. 88). O autor cita que essa imagem canônica globalizada tem sofrido alterações na sua representação, mas foi incorporada ao consciente coletivo e a base evolutiva permaneceu. É uma ideia ocidental de evolução como progresso tendo como o ápice o ser humano.

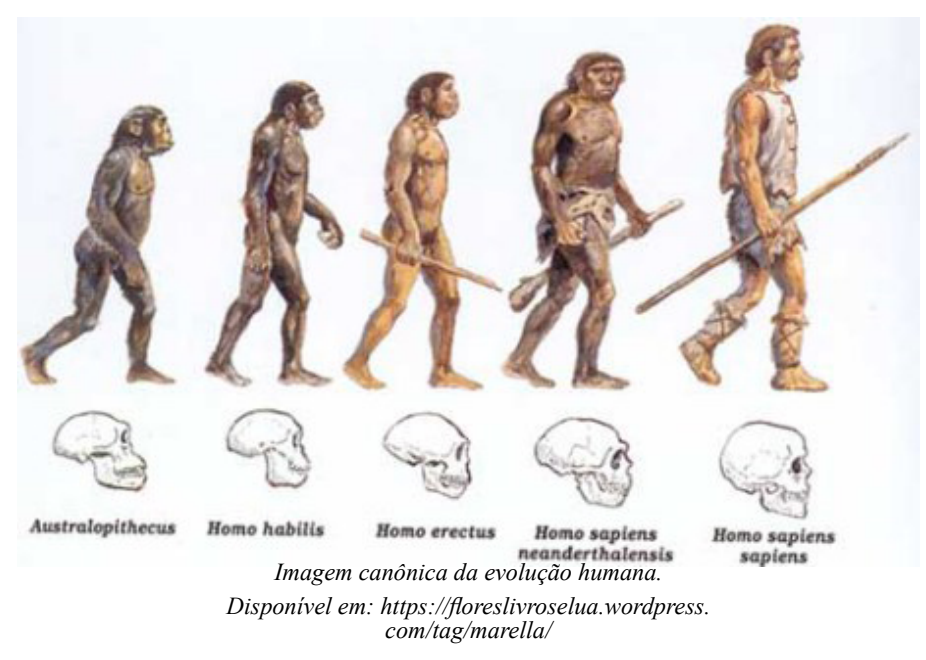

Ao pensamento de Morin, Saliba vem corroborar, quando aponta (2011, p. 90): “(...) o aluno deve observar, classificar, analisar, descobrir, em síntese, operar um ordenamento no tempo". De modo que o aluno consiga em operação crítica, se identificar e também se distanciar quando for preciso, quebrando com o efeito do real que as imagens provocam.

A imagem da evolução humana apresentada nos leva a entender que o período anterior é sempre inferior ao seguinte, nos apontando para um pensamento sobre a civilização e cultura de maneira etapista, dita anteriormente como primitiva, apenas é diferente. Afinal, o importante é compreender que cada fase da história tem seu "desenvolvimento" próprio, sem deixar de ter o seu valor em si mesmo.

Saliba (2011) salienta a importância de apresentar aos alunos imagens não canônicas, que retratam a realidade por meio da história, relacionando imagens com o contexto histórico, político, econômico e social. É o caso da imagem abaixo, que embora apresentando os escravos brasileiros bem vestidos, não utilizavam calçados. Representando que não eram libertos, pois o uso de sapatos simbolizava status de liberdade. Mesmo quando os sapatos não lhes serviam ou não se acostumavam a andar calçados, eles os carregavam sobre seus ombros para explicitar sua condição de livres. 


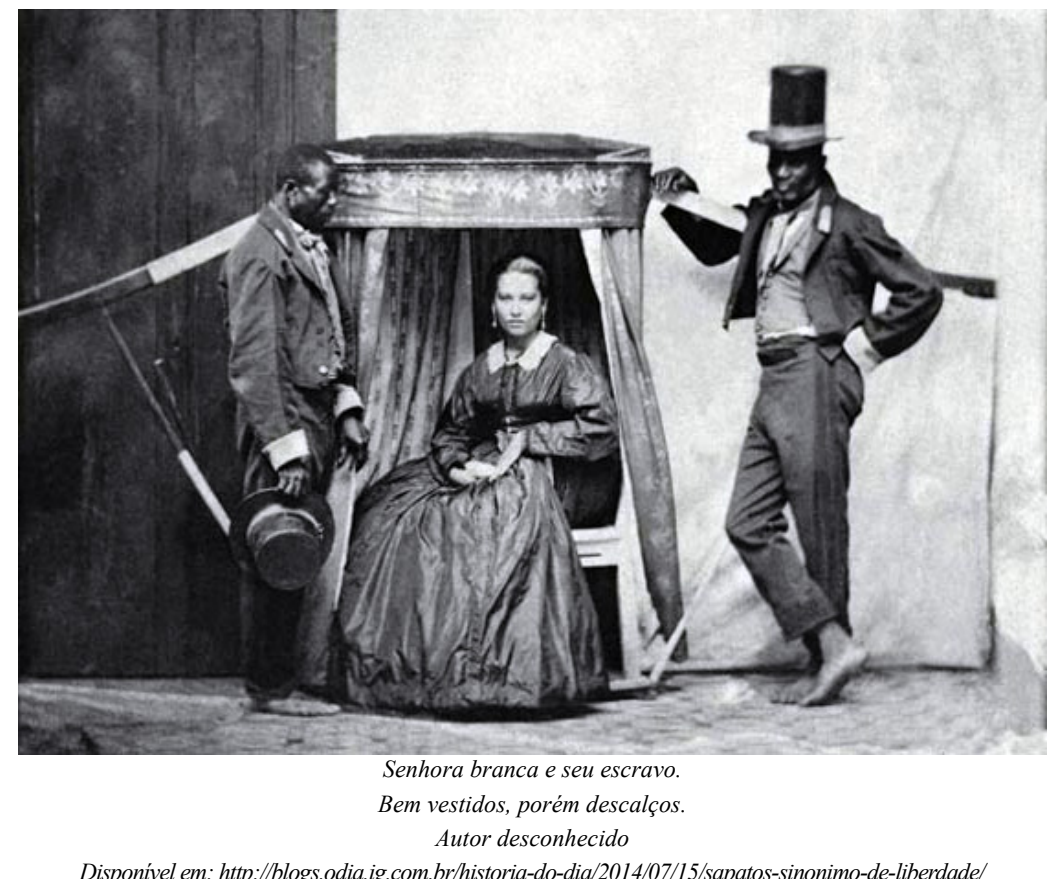

Disponivel em: http://blogs.odia.ig.com.br/historia-do-dia/2014/07/15/sapatos-sinonimo-de-liberdade/

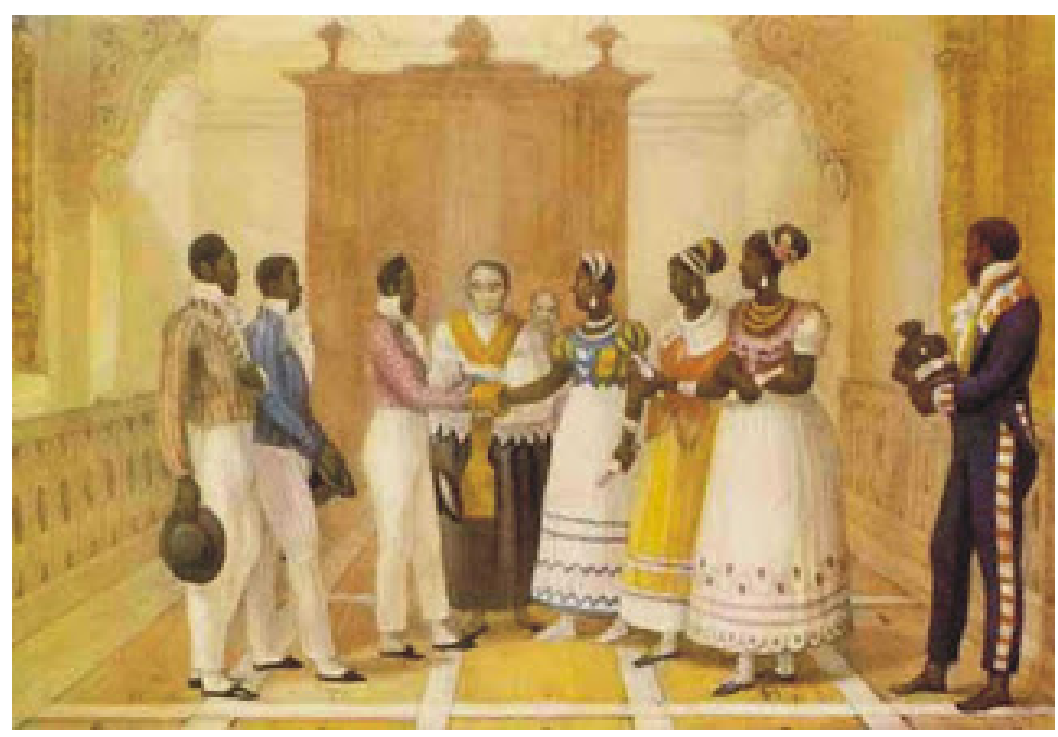

Jean-Baptiste Debret (1768-1848)

"Casamento de negros escravos de uma casa rica", 1839.

Litografia sobre papel, $32 \times 23 \mathrm{~cm}$.

Pinacoteca do Estado de São Paulo.

Segundo Luiz (2008), os negros apareceram em poucas representações iconográficas e quando apareciam sempre eram representados pela etnia; nunca pelos seus nomes e quase sempre estereotipados. Esse mesmo autor apresenta que é muito comum em alguns livros didáticos a existência de imagens de negros escravos relacionados aos serviços que eram submetidos, a cenas de punição sendo assistida passivamente por um grupo de negros escravos ou por outro que realiza as suas tarefas com indiferença ao ocorrido. Essas imagens sendo apresentadas desse modo reduzem o conhecimento do aluno com relação à vida do negro, restringindo-se somente à escravidão, pois tais imagens apresentam os negros conformados com o seu status quo, desprovidos de práticas de resistência em grupo e de pertencerem a uma cultura. No entanto, Luiz (2008) aponta 
que existiam negros livres, como é o caso de Luiz Gama (1830-1882), abolicionista e advogado, tal fato reforça a ideia de que existiam negros intelectuais no século XIX, rompendo com a relação do modelo do negro deste século ligado somente à escravidão, pobreza e violência.

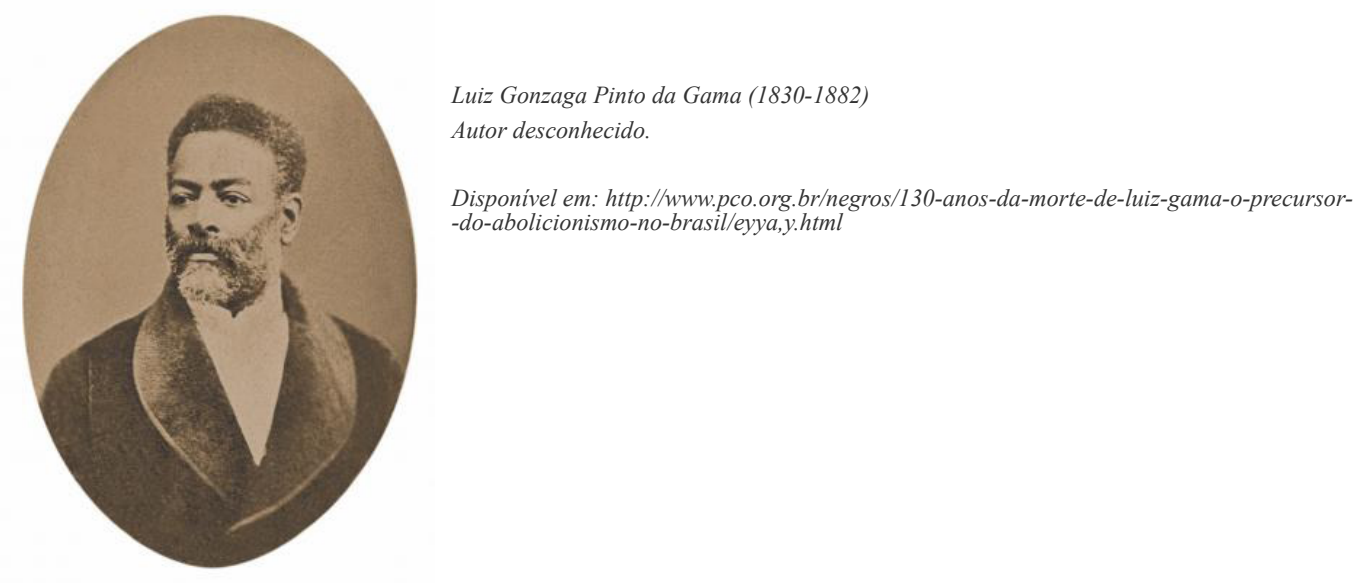

Uma vez o educador buscando apresentar as imagens que representam um tema de forma crítica e contextualizada, o aluno terá mais possibilidade de construir uma aprendizagem significativa, sendo que terá uma compreensão do todo e das partes, como nos aponta Morin:

Pascal já formulara a necessidade de ligação, que hoje é o caso de introduzir em nosso ensino, a começar pelo primário: "Sendo todas as coisas causadas e causadoras, ajudadas e ajudantes, mediatas e imediatas, e todas elas mantidas por um elo natural e insensível, que interliga as mais distantes e as mais diferentes, considero impossível conhecer as partes sem conhecer o todo, assim como conhecer o todo sem conhecer, particularmente, as partes. (MORIN, 2003, p. 25).

Esse princípio formulado por Morin é muito importante para o ensino, principalmente nos dias atuais, quando as imagens são trazidas para o espaço escolar por meio de novas tecnologias e multimídias e, considerando que o aluno já tem acesso de forma exacerbada às imagens em tempo real em seu cotidiano, por meio de programas televisivos, cinema, vídeos, internet, jogos eletrônicos e propagandas, compete ao professor ser criterioso ao selecionar as imagens, evitando o transbordamento destas em sala de aula, de maneira exagerada, descontextualizada e superficial.

Segundo Saliba (2011, p. 90), "as imagens em excesso, parece, acabam matando ou banalizando aquilo que poderíamos chamar de nossa inteligência da imagem". Cabe ao professor o discernimento de não intoxicar seus alunos de imagens, mas, ao fazêlo, perceber se existe uma motivação e atenção discriminatória e crítica, importante em qualquer aprendizagem. Saber buscar o que a imagem observada representa, simboliza e significa, examinando seu contexto e intenção é de fundamental importância.

Essa análise envolve não apenas as imagens apresentadas nos livros didáticos, mas aquelas que são apresentadas como verdades nos noticiários, filmes e vídeos. $\mathrm{O}$ educando, nesse processo de formação, construirá seu conhecimento à medida que receba 
ferramentas vindas de um mediador, para analisar e perceber as intenções por trás das imagens vistas, sabendo que as imagens são construídas com um propósito.

Horkheimer e Adorno (2002) afirmam que as imagens muitas vezes são utilizadas a serviço do mercado e para fins econômicos, abordando o caso de filmes e televisão. Podemos aferir que, principalmente, o sentido da propaganda é levar o espectador a ser cliente e este ao consumo, que nem sempre é fruto da necessidade, mas da ideia massificadora do desejo que se transforma em necessidade. Assim, ao apresentar imagens e filmes, cabe ao professor, mediar a avaliação e análise que o aluno fará a respeito do que viu e ouviu.

Deste modo, na preparação da aula, o professor classificará as imagens que serão apresentadas, podendo ser canônicas ou não canônicas, do passado ou presente, desde que tenham por objeto o ensino. Sejam elas gravuras ou vídeos, devem ser escolhidas de acordo com aquilo que se queira ensinar ao aluno, não apenas porque é uma imagem bela ou um filme famoso. Precisam ser acompanhadas de seus significados no tempo cronológico da história das sociedades:

Nesse sentido, são imagens que podem ajudar a integrar criticamente o aluno numa comunidade de significados - o que se chama hoje de imaginário da sociedade [...] os melhores filmes e as melhores imagens são aquelas capazes de nos provocar uma reação emocional, fugindo à banalização e a seriação das imagens canônicas (SALIBA, 2011, p. 95).

Temos que levar em consideração toda a emoção que a obra de arte produz, e sabermos que nem todas elas são explicadas pela "razão" e pelo "porque", porém podemos tomar as palavras de Franca (2006, p. 190) quando registra a respeito do trabalho artístico: "Antes de se impor como instrumento de comunicação, o trabalho é feito para significar (aquilo que as coisas querem dizer), pois todo trabalho adquire um sentido amplo quando endereçado a alguém e entendido por ele".

Precisamos esclarecer que relacionar a imagem com o que ela significa no sentido de explorar o que "ela quis dizer", relacionado com fatos históricos, não anula o extrapolar a razão que a obra de arte nos apresenta. Embora as obras de artes possuam "explicações" subjetivas, quando presentes em livros didáticos e utilizadas em disciplinas, devem sim, envolver a razão.

A razão está assim intrinsecamente presente no objeto artístico, mas a obra enfeixa elementos que escapam ao domínio do racional e sua comunicação conosco se faz por outros canais: da emoção, do espanto, da intuição, das associações, das evocações, das seduções. Posso descrever uma obra, desenvolver uma análise, assinalar este ou aquele problema, propor relações e comparações. Entretanto, tudo isso significa apenas indicar alguns modos de aproximação do objeto artístico, nunca esgotá-lo. O artista nos dá a perceber sua obra por modos que posso talvez nomear, mas que escapam ao discurso, pois jamais deixarão de pertencer ao campo do não racional. (COLI, 1995, p. 104)

Meneses (2003, p. 28) afirma que as imagens não possuem sentido em si mesmas, 
pois são artefatos; segundo o autor, os sentidos são definidos pela interação social, que acontecem em um tempo, espaço e circunstâncias sociais e, segundo ele:

Daí não se poder limitar a tarefa à procura do sentido essencial de uma imagem ou de seus sentidos originais, subordinados às motivações subjetivas do autor, e assim por diante. É necessário tomar a imagem como um enunciado, que só se apreende na fala, em situação. Daí também a importância de retraçar a biografia, a carreira, a trajetória das imagens.

Franca (2006) também aborda um momento em que convergem o olhar e o pensar, à medida que examina o lugar da imagem. Em um dos aspectos, a autora afirma que esse lugar também é o da reflexão.

Embora a autora afirme que uma imagem possa ter mil sentidos e versões, citando, por exemplo, a cor que transborda os significados, ela utiliza de meios para comunicar-se.

Podemos afirmar que, utilizadas dentro dos livros didáticos, elas estão vinculadas ao que querem comunicar; assim tornam-se explicativas dos verbos e palavras que a acompanham e por eles são explicadas.

A mesma imagem pode ser utilizada de várias maneiras, à medida que se altera o foco ou objetivo que se queira atingir e qual informação ou conhecimento se queira ensinar e compartilhar. Pode ser abordada em vários aspectos.

Meneses (2003, p. 29) aborda o uso de imagens como fonte de informação em seus múltiplos papéis:

O emprego de imagens como fonte de informação é apenas um dentre tantos (inclusive simultaneamente a outros) e não altera a natureza da coisa, mas se realiza efetivamente em situações culturais específicas, entre várias outras. A mesma imagem, portanto, pode reciclar-se, assumir vários papéis, ressemantizarse e produzir efeitos diversos.

Franca (2006), em seu artigo, faz referência à existência da litosfera, atmosfera, biosfera e zoosfera e afirma que a iconosfera (imagem) deva sair do ambiente frio e silencioso dos museus, juntando-se à logosfera (palavras), que segundo ela torna-se produtiva. Em suas palavras:

A iconosfera, esse mundo calmo e silencioso da imagem pousado em museus, galerias, e gabinetes de colecionadores, sempre fica ameaçada de asfixia. É preciso dar a ela uma contribuição borbulhante de junção com a logosfera. Só assim ela conseguirá aglutinar os espíritos, como faz a árvore que, prisioneira de suas raízes, aproveita o vento murmurante para espalhar seu pólen e grãos volantes sobre toda a planície (TOURNIER, 1988 apud FRANCA, 2006, p. 200).

Tendo em mente que Arte também é disciplina e que, portanto, deve integrar o Projeto Político Pedagógico de todas as escolas, fazendo parte de um contexto 
interdisciplinar ${ }^{2}$, em que uma disciplina é complementada e elucidada pela outra em um programa escolar completo e integrado, salientamos a importância do que afirmam Mosaner Jr. e Stori (2007, p. 144):

(...) é necessário que encarem a arte como uma disciplina que tem de estar no mesmo patamar de igualdade que as demais disciplinas que compõem o currículo e não colocada como um simples apêndice, um enfeite, uma atividade extraclasse ou uma forma de lazer. É importante que percebam que arte tem uma linguagem, uma história, um domínio próprio, isto é, conteúdo próprio.

Expor os conteúdos da Arte de maneira contextualizada, para Barbosa (2012, p.34), não se alude em apresentar simplesmente os fatos históricos e a vida do artista, mas "é pôr a obra em contexto que faz produzir sentido na vida daqueles que a observam", é permitir que cada um encontre, a partir da obra apresentada, seu devir artista.

Podemos pensar em Arte como facilitador da aprendizagem, que proporciona a criatividade, imaginação, sensibilidade e desenvolve o hábito de "ler o mundo" em todos os seus aspectos, inclusive naqueles que envolvem outros saberes. Fazemos nossas as preciosas palavras de Barbosa (2012, p. 4):

Arte não é apenas básica, mas fundamental na educação de um país que se desenvolve. Arte não é enfeite, Arte é cognição, é profissão, é uma forma diferente da palavra para interpretar o mundo, a realidade, o imaginário, e é conteúdo. Como conteúdo, arte representa o melhor trabalho do ser humano.

\section{Considerações finais}

Este trabalho trouxe-nos reflexão sobre as imagens apresentadas aos alunos pelos livros didáticos, em forma de vídeos e figuras apresentados em aula. Nosso desejo é de que elas saiam do papel não apenas como "ilustrações" que embelezam os livros, ou vídeos, mas como imagens que possam germinar reflexões sobre o contexto em que foram pintadas ou compostas, buscando a compreensão e apreciação da obra artística e as relações com os conteúdos e conceitos abordados.

Quem sabe, possibilitar aos alunos sugestões para unir disciplinas, como a Arte e História, de modo interdisciplinar, em que cada aluno, individualmente ou em grupo, utilizaria a percepção, e a criatividade, dando a "sua" visão a respeito do assunto estudado e temas abordados ao final da etapa? A produção poderia fruir a partir do que apreenderam, dando "asas à imaginação", fluindo emoções e sensibilidade, desprendendo-se das cores e formas das imagens apresentadas, para extrapolar e espalhar o pólen da criação por toda a superfície do seu aprendizado. Esse projeto artístico poderia ser apresentado por meio das artes plásticas, utilizando pintura, escultura, performance, instalações, assim como pela música, dança, teatro ou outras linguagens artísticas.

Não queremos dizer que o estudo de Arte deva permanecer vinculado como um

2 Interdisciplinaridade, segundo Lenoir (1998), requer pelo menos duas disciplinas ou mais, conforme o próprio nome revela, em uma ação recíproca e de interação. A interdisciplinaridade não é contrária à perspectiva da disciplina, mas alimenta-se dela e não pode existir sem ela. 
aporte às outras disciplinas, pois acreditamos em Arte como disciplina, que apresenta seus conteúdos específicos, não se limitando dentro da escola apenas à confecção de enfeites para datas comemorativas; ou exposta em imagens de livros e vídeos.

A intersecção entre as diversas áreas do conhecimento em um movimento interdisciplinar e a valorização de todas as linguagens em igualdade de importância deve ser a base da ação pedagógica para que os educandos se tornem protagonistas na construção de saberes, ampliando suas possibilidades de se expressar e de compreender o mundo.

\section{Referências}

AMÉRICO, P. (1843-1905). “Independência ou Morte”, 1888. Óleo sobre tela, 415cm x $760 \mathrm{~cm}$. Museu Paulista USP, SP.

AMÉRICO, P. (1843-1905). “Tiradentes Esquartejado", 1893. Óleo sobre tela, $270 \mathrm{~cm} \times$ $165 \mathrm{~cm}$. Museu Mariano Procópio, MG.

BARBOSA, A. M. T. B. A imagem no ensino da arte. 8. ed. São Paulo: Perspectiva, 2012.

BENJAMIN, W. A obra de arte na era de sua reprodutividade técnica. Trad. José Lino Grünnewald. Coleção Os pensadores. Rio de Janeiro: Abril Cultural, 1955.

COLI, J. O que é arte. 15. ed. São Paulo: Editora Brasiliense, 1995.

DEBRET, J. (1768-1848). "Casamento de negros escravos de uma casa rica", 1839. Litografia sobre papel, 32 x $23 \mathrm{~cm}$. Pinacoteca do Estado de São Paulo.

LENOIR, Y. "Didática e interdisciplinaridade: uma complementaridade necessária e incontornável”. In: Didática e interdisciplinaridade. FAZENDA, I. (org.). Campinas: Papirus, 1998.

FRANCA, P. “O Lugar da Imagem”. In: NAZARIO, L.; FRANCA, P. (org.). Concepções contemporâneas da arte. Belo Horizonte: Editora UFMG, 2006. p. 190-202.

HORKHEIMER, M.; ADORNO, T. "A indústria cultural: o iluminismo como mistificação de massas". p. 169 a 214. In: LIMA, Luiz Costa. Teoria da cultura de massa. São Paulo: Paz e Terra, 2002. 364p.

MENESES, U. T. B. "Fontes visuais, cultura visual, História visual. Balanço provisório, propostas cautelares”. In: Revista Brasileira de História. São Paulo, v. 23, n 45, p. 11 36, jul. 2003.

MORIN, E. A cabeça bem-feita: repensar a reforma, reformar o pensamento. Tradução: Eloá Jacobina. - 8. ed. Rio de Janeiro: Bertrand Brasil, 2003.

MOSANER JR, E.; STORI, N. 'O ensino das artes no Brasil'. In: Sinergia, São Paulo, v.8, no 2, p. 144-150, jul./dez. 2007. 
PORTINARI, C. (1903 -1962). "Painel Tiradentes" (detalhe), 1949. Memorial da América Latina, SP.

RODRIGUES. J. W. (1891-1957). “Alferes Joaquim José da Silva Xavier, o Tiradentes" (detalhe), 1940. Óleo sobre tela, 156,5 cm x 98 cm. Museu Histórico Nacional, RJ.

SALIBA, E. T. “As imagens canônicas e a História”. In: CAPELATO, M. H. et al. História e cinema: Dimensões históricas do audiovisual. 2. ed. São Paulo: Alameda, 2011, p. 85-96.

VILLARES, D. (1851-1931). “Tiradentes”. Litogravura, 1890. Museu Histórico Nacional, RJ.

\section{Livros didáticos examinados:}

BOULOS JÚNIOR, A. História sociedade $\&$ cidadania $-9^{\circ}$ ano. 2. ed. São Paulo: FTD, 2012.

FREITAS NETO, J. A.; TASINAFO, C. R. História Geral e do Brasil. São Paulo: Harbra, 2006.

VAZ, M. L. Jornadas.hist: história - $9^{\circ}$ ano. São Paulo: Saraiva, 2012.

Sites:

ALL POSTERS. Disponível em: $\leq$ http://www.allposters.com.br/-sp/Trabalhadores-daconstrucao-fazem-pausa-para-almoco-em-viga-de-aco-em-cima-do-predio-da-RCA-noRockefeller-Center-posters_i3710031_htm>. Acesso em: 1 mai. 2015.

CAUSA OPERÁRIO ONLINE. "130 anos da morte de Luiz Gama, o precursor do abolicionismo no Brasil". Disponível em: $\leq$ http://www.pco.org.br/negros/130-anos-damorte-de-luiz-gama-o-precursor-do-abolicionismo-no-brasil/eyya,y.html $>$. Acesso em: 24 mai. 2015.

DELPINO, A. A. F. (1864 - 1942). “Tiradentes enforcado". Disponível em: $\leq$ http:// pt.wikipedia.org/wiki/Alberto_Delpino>. Acesso em: 23 mai. 2015

FLORES, LIVROS E LUA BLOG. Disponível em: $\leq$ https://floreslivroselua.wordpress. com/tag/marella/>. Acesso em: 10 mai. 2015.

FUNDAÇÃO MUSEU MARIANO PROCÓPIO. Disponível em: $\leq$ http://mapro.pjf. mg.gov.br/>. Acesso em: 1 mai. 2015.

GNOTÍCIAS. $\leq \mathrm{http}$ ://noticias.gospelmais.com.br/tv-apresentadora-jesus-brancocriticada-convidado-63444.html>. Acesso em: 10 mai. 2015.

IMAGEM DO TEMPO. Disponível em: $\leq \mathrm{http}: / /$ imagemetempo.blogspot.com.br/2011/05/ sapatos-para-escravos-simbolo-de.html>. Acesso em: 13 abr. 2015. 
INSTITUTO HISTÓRICO E GEOGRÁFICO DE SANTOS. Disponível em: $\leq$ http:// www.ihgs.com.br/cadeiras/patronos/joaquimjose.html>. Acesso em: 13 abr. 2015.

LUIZ, J. M. "Iconografia e livro didático de história: Um outro olhar acerca das representações imagéticas sobre as populações negras". 2008. Disponível em: $\leq \mathrm{http}$ //Www.anpuhpb.org/anais_xiii_eeph/textos/ST\%2016\%20\%20Janailson\%20 Mac\%C3\%AAdo\%20Luiz\%20TC.PDF>. Acesso em: 18 abr. 2015.

MOURA, A. História do Dia. Disponível em: $\leq$ http://blogs.odia.ig.com.br/historia-dodia/2014/07/15/sapatos-sinonimo-de-liberdade/>. Acesso em: 13 abr. 2015.

MUSEUHISTÓRICONACIONAL.Disponívelem: $\leq$ http://www.museuhistoriconacional. com.br/>. Acesso em: 1 mai. 2015.

MUSEU PAULISTA - USP. Disponível em: $\leq$ http://www.mp.usp.br/node/4109>. Acesso em: 1 mai. 2015.

PINACOTECA DO ESTADO DE SP. Disponível em: $\leq$ http://www.pinacoteca.org.br/ pinacoteca-pt/default.aspx $? \mathrm{mn}=545 \& \mathrm{c}=$ acervo\&letra $=\mathrm{J} \& \mathrm{~cd}=3571>$. Acesso em: 1 mai. 2015.

PORTAL DO ESPÍRITO. Disponível em: $\leq$ http://www.espirito.org.br/index.html>. Acesso em: 10 mai. 2015. 